\title{
Impact of psychiatric comorbidity on the severity, short-term functional outcome, and psychiatric complications after acute stroke
}

This article was published in the following Dove Press journal:

Neuropsychiatric Disease and Treatment

\author{
Carolin Hoyer' \\ Hanna Luise Schmidt' \\ Laura Kranaster ${ }^{2}$ \\ Angelika Alonso' \\ 'Department of Neurology, \\ Universitätsmedizin Mannheim, \\ University of Heidelberg, Mannheim, \\ Germany; ${ }^{2}$ Department of Psychiatry and \\ Psychotherapy, Central Institute of \\ Mental Health, Medical Faculty \\ Mannheim, Heidelberg University, \\ Mannheim, Germany
}

Correspondence: Carolin Hoyer Department of Neurology, Universitätsmedizin Mannheim, University of Heidelberg, Theodor-Kutzer-Ufer I-3, Mannheim 68167, Germany

Tel +4962I 3832885

Fax +496213832884

Email carolin.hoyer@umm.de
Background and purpose: The comorbidity of psychiatric disorders and cerebrovascular disease appears to be complex with underlying bidirectional influences. Hitherto, research has focused mainly on the evaluation of stroke risk in particular psychiatric disorders; only a few studies have assessed their role in the acute natural history of stroke. The aim of this study was to provide a perspective on psychiatric premorbidity and its impact on stroke severity, psychiatric complications during the initial treatment phase, and the short-term functional outcome of stroke. Patients and methods: We retrospectively studied the impact of a predocumented psychiatric diagnosis (PDPD) on stroke severity, short-term functional outcome, and psychiatric complications in a sample of 798 patients consecutively admitted for acute ischemic or hemorrhagic stroke by performing a chart review. Group comparisons (PDPD vs non-PDPD) with adjustment for covariates were carried out either using multivariate analysis of variance or logistic regression analysis.

Results: More severe strokes (ie, mean National Institute of Health Stroke Scale score on admission $10.1 \pm 7.9$ vs $7.5 \pm 7.4 ; \mathrm{F}(10,796)=18.5, p<0.0001)$ and higher prevalence of poor outcome (73.7 vs 54.9\%; OR: 2.6, standard error: $0.5, \mathrm{z}=4.82, p<0.0001$ ) was found in patients with a documented psychiatric diagnosis at the time of stroke, as well as a higher rate of psychiatric complications during the initial treatment phase ( 46.7 vs $28.9 \%$; OR: $-0.78, z=4.59, p<0.0001$ ).

Conclusion: Our data have clinical implications in that they call for identification of psychiatric premorbidity or comorbidity through careful history-taking and particularly close monitoring for psychiatric complications with respect to their potentially negative impact on outcome after stroke.

Keywords: stroke, psychiatric disorder, comorbidity

\section{Introduction}

Stroke is one of the major causes of disability and death worldwide. ${ }^{1-3}$ Nonmodifiable (eg, age, sex, race or ethnicity, and heredity) and modifiable (eg, diabetes, atrial fibrillation, smoking, dyslipidemia, and arterial hypertension) risk factors for stroke have been extensively studied. ${ }^{4,5}$ In addition, a variety of factors impacting on initial stroke severity and prognosis after stroke have been identified: beyond predictors such as age, gender, National Institute of Health Stroke Scale (NIHSS) score at admission, and fever, ${ }^{6}$ metabolic and cardiovascular comorbidities - diabetes, prior stroke, and atrial fibrillation in particular ${ }^{3,7,8}$ - negatively influence long-term functional outcome in stroke survivors.

Depression, anxiety, psychosis, or dementia are frequent and relevant comorbidities of stroke. Poststroke depression, for example, affects nearly a third of all stroke 
survivors within five years following stroke, ${ }^{9}$ and poststroke depression severity predicts the extent of impairment in activities of daily living after stroke. ${ }^{10}$ Pre-existing affective disorder, on the other hand, has been demonstrated to predict more severe strokes on admittance and to negatively impact functional and cognitive outcomes after stroke. ${ }^{11,12}$ Recent data from a large Swedish register study indicate that patients with prestroke psychosis showed a poorer outcome and poorer utilization of secondary pharmacological prevention after stroke. ${ }^{13}$ While prevalence data regarding the occurrence of poststroke delirium vary between 13 and $48 \%$, this condition leads to prolongation of hospital stay, poorer functional outcome, and increased risk for developing dementia. Dementia affects approximately $10 \%$ of patients after first stroke and $30 \%$ after recurrent stroke, ${ }^{14}$ stressing the causal relevance of stroke per se for the development of dementia independently of underlying vascular risk factors.

Apart from a mere co-occurrence due to high prevalence of psychiatric and cerebrovascular disease, shared risk factors or pathomechanisms as well as complex causative relationships may be invoked to explain their coexistence. To begin with, delirious or depressive syndromes may ensue from cerebrovascular events, with characteristics such as stroke severity, lesion size, and lesion location conferring various degrees of risk for these complications. ${ }^{10,15,16}$ Second, there is a large body of research investigating the presumably bidirectional - relationship between vascular risk factors and psychiatric disorders like affective disorders or schizophrenia. ${ }^{17-19}$ There is also evidence for deeper underlying relationships: biological changes associated with affective disorders include, among others, increased inflammation, overactivity of the hypothalamus-pituitary-adrenal axis, and endothelial dysfunction, which in turn may comediate the link to vascular disease and, eventually, stroke. ${ }^{20,21}$ Based on data from functional genomic analyses, it has also been suggested that schizophrenia may be a vascularischemic and postischemic repair disorder. ${ }^{22}$ Finally, aspects related to the treatment of psychiatric conditions may pertain to their co-occurrence with cerebrovascular disease, as an increased risk of stroke has been found in association with antipsychotic pharmacotherapy. ${ }^{23}$

Specific psychiatric disorders such as affective disorders, schizophrenia, and dementia have mainly been studied with a focus on the evaluation of risk for stroke or their role in recovery or longer-term outcome in the wake of a stroke. ${ }^{19,24-26}$ Rarely, however, has a general perspective on psychiatric premorbidity and stroke risk $^{27,28}$ or its impact on stroke severity on admission been taken. We aim to elaborate on this issue through a retrospective analysis of stroke patients' documented pre-existing psychiatric diagnoses and severity and short-term functional outcome of stroke.

\section{Methods}

\section{Patients}

The study was approved by the ethics committee (Ethikkommission II der Universität Heidelberg Medizinische Fakultät Mannheim) and performed in accordance with the Code of Ethics of the World Medical Association (Declaration of Helsinki). Written informed consent was obtained from all participants prior to enrolment. We retrospectively analyzed medical data of 798 patients consecutively admitted to the stroke unit of the University Medical Centre, Mannheim, Germany, for acute ischemic or hemorrhagic stroke between January and December 2016. The study was approved by the local ethics committee. Cases of cerebral ischemia or intracranial hemorrhage due to trauma, infection, vascular malformation, or cerebral venous thrombosis were not included in the study.

\section{Measures}

The necessary information was obtained through a retrospective chart review. As the predictor variable, a predocumented psychiatric diagnosis (PDPD) was defined. Possible covariates were basic demographic information such as age and sex as well as the prevalence of preexisting cardiovascular risk factors and the premorbid modified Rankin Scale (mRS) score. Outcome variables were subdivided into variables indicating the clinical severity of the index stroke (NIHSS and mRS scores on admission, "minor stroke" with initial NIHSS score $<4$, NIHSSS at discharge), variables indicating the short-term functional outcome (mRS score at discharge, death, and "poor outcome" with $\mathrm{mRS}>2$ at discharge), treatmentrelated outcome variables (duration of hospitalization, acute therapy for ischemic stroke), and variables for the outcome of psychiatric complications during the hospitalization for stroke (defined as newly diagnosed delirium or depressive syndrome - both as judged by the treating physician, new prescription of an antidepressant, antipsychotic, or benzodiazepine, dosage increase of pre-existing psychiatric medication, or requirement for physical restraint). 
Any PDPD independent of acuity at the time of hospitalization for stroke was recorded in accordance with the ICD-10: F0x (dementia - delirium was excluded, see below), F1x (substance-associated disorders excluding tobacco, which was recorded separately), F2x (schizophrenia and related disorders), F3x (affective disorders), and F4x (anxiety, somatic-neurotic-stress disorders). We separately noted whether there was a history of delirium. Preexisting psychiatric medication was classified into antidepressant, antipsychotic, and antidementive medication and benzodiazepines.

\section{Statistical analysis}

Unless differently indicated, all values are expressed as mean \pm SD. Statistics were performed using STATA ${ }^{\circledR}$ (version 11; StataCorp LP, College Station, TX, USA) at a significance level $\leq 0.05$. The Kolmogorov-Smirnov goodness-of-fit test was used to test normality and as the data were normally distributed, parametric tests could be used. The distribution of categorical variables such as demographic variables, vascular risk factors, and psychiatric complications between both groups was compared by chisquare tests, and Fisher's exact test in the case of small cell sizes. Group comparisons of continuous variables such as age were assessed using independent-samples $t$-tests. Age, sex, and the prevalence of pre-existing cardiovascular risk factors were assumed to be covariates, and thus group comparisons (PDPD vs non-PDPD) for dichotomous outcome variables such as minor stroke, poor outcome, or death were carried out using logistic regression analysis in order to adjust for the covariates. Accordingly, group comparisons for continuous outcome variables such as mean NIHSS or mRS scores were carried out using multivariate analysis of variance to adjust for the covariates mentioned. A subgroup analysis of PDPD patients with the exclusion of patients with dementia was intended, because it could be at least argued to count dementias as neurodegenerative diseases in the category of psychiatric disorders.

\section{Results}

\section{Demographic information and predocumented psychiatric diagnoses}

798 patients were included in our analysis; 599 were regarded as non-PDPD patients, whereas 199 patients were PDPD patients. Demographic information is summarized in Table 1. PDPD and non-PDPD patients did not differ in terms of age (71.9 vs 71.8 years) or sex (54.8 vs $58.8 \%$ male). Differences between the groups were found regarding living circumstances prior to the index stroke, with PDPD patients living significantly more frequently under family $(p<0.0001)$ or institutional $(p<0.0001)$ care and significantly less frequently at home in an independent manner $(p<0.0001)$. In concordance

Table I Demographic information and vascular risk factors compared between PDPD and non-PDPD patients

\begin{tabular}{|c|c|c|c|}
\hline & PDPD patients $(n=199)$ & Non-PDPD patients $(n=599)$ & $p$-value \\
\hline \multicolumn{4}{|l|}{ Demographics } \\
\hline Age (years), mean (SD) & $71.9(14.5)$ & $71.8(12.8)$ & 0.972 \\
\hline Sex (male), n (\%) & $109(54.8)$ & $352(58.8)$ & 0.323 \\
\hline \multicolumn{4}{|c|}{ Living circumstances prior to index stroke } \\
\hline Independent at home, n (\%) & II 5 (57.8) & $523(87.3)$ & 0.001 \\
\hline Family care, n (\%) & $4 I(20.6)$ & $55(9.2)$ & 0.001 \\
\hline Institutional care, n (\%) & $43(21.6)$ & $21(3.5)$ & 0.001 \\
\hline Premorbid mRS score (mean, \pm SD) & $2.1(1.8)$ & I.0 (I.4) & 0.001 \\
\hline \multicolumn{4}{|l|}{ Vascular risk factors } \\
\hline Hypertension, n (\%) & 153 (76.9) & $496(82.8)$ & 0.083 \\
\hline Diabetes mellitus, $\mathrm{n}(\%)$ & $58(29.1)$ & $194(32.4)$ & 0.417 \\
\hline Dyslipidemia, n (\%) & $51(25.6)$ & $194(32.4)$ & 0.080 \\
\hline Coronary heart disease, $\mathrm{n}(\%)$ & $27(13.6)$ & $111(18.5)$ & 0.115 \\
\hline Prior myocardial infarction, $\mathrm{n}(\%)$ & $16(8.0)$ & $54(9.0)$ & 0.687 \\
\hline Prior stroke, n (\%) & $45(22.6)$ & $119(19.9)$ & 0.388 \\
\hline Current or past smoker, n (\%) & $58(29.1)$ & $108(18.0)$ & 0.001 \\
\hline
\end{tabular}

Note: Bold data indicate statistical significance.

Abbreviations: mRS, modified Rankin Scale; PDPD, predocumented psychiatric diagnosis. 
with this, premorbid mRS scores differed between the groups (median mRS scores 2 vs $0 ; p<0.0001$ ).

Concerning vascular risk factors, no differential distribution was found between PDPD and non-PDPD patients except for smoking, where past or present tobacco consumption was more frequent among PDPD patients $(29.1$ vs $18.0 \% ; p=0.001)$.

In the group of patients with psychiatric comorbidity, the most frequent PDPDs were substance-associated $(35.7 \%)$ and affective (34.2\%) disorders, as well as dementia (34.7\%). Table 2 provides a more detailed overview of the PDPDs and of the subclasses of medication recorded in the PDPD. Psychiatric polypharmacy (ie, more than one medication from the classes listed above) was found in 18 PDPD patients.

\section{Index stroke - severity, treatment, functional outcome}

All reported group comparison results between PDPD and non-PDPD patients concerning the index stroke are adjusted for age, sex, and vascular risk factors in order to control for potentially confounding factors.

No differences were noted regarding the frequency of ischemic vs hemorrhagic stroke between the groups

Table 2 Predocumented psychiatric diagnosis (PDPD) and psychiatric medication in PDPD patients

\begin{tabular}{|l|l|}
\hline PDPD & Patients, $\mathbf{n}$ (\%) \\
\hline F0 & $69(34.7)$ \\
FI & $71(35.7)$ \\
F3 & $8(4.0)$ \\
F4 & $68(34.2)$ \\
History of delirium & $17(8.5)$ \\
\hline Medication & $14(7.0)$ \\
\hline Antidepressant & \\
SSRI & $58(29.1)$ \\
Tricyclic & $45(22.6)$ \\
\hline Benzodiazepine & $19(9.6)$ \\
\hline Antipsychotic & $11(5.5)$ \\
\hline First generation, high potency & $33(16.6)$ \\
First generation, low potency & $3(1.5)$ \\
Second generation & $19(9.6)$ \\
\hline Antidementive & $14(7.0)$ \\
\hline
\end{tabular}

Notes: F0, dementia (delirium was excluded); FI, substance-associated disorders (excluding tobacco, which was recorded separately); F2, schizophrenia and related disorders; F3, affective disorders; F4, anxiety, somatic-neurotic-stress disorders $(p=0.24)$ (Table 3). Stroke severity was more pronounced in PDPD patients on admission (mean NIHSS score 10.1 \pm 7.9 vs 7.5 $\pm 7.4 ; \mathrm{F}(10,796)=18.5, p<0.0001)$ and on discharge (mean NIHSS score $9.7 \pm 12.0$ vs $6.3 \pm 10.0 ; \mathrm{F}(10,796)=15.3$, $p=0.0001$ ). Functional impairment was also more severe in this patient population as evidenced by higher mRS scores on admission $(4.1 \pm 1.1$ vs $3.6 \pm 1.3 ; \mathrm{F}(10,796)=25.6, p<0.0001)$ and discharge $(3.7 \pm 1.6 \quad$ vs $2.9 \pm 1.7 ; \quad \mathrm{F}(10,796)=32.1$, $p<0.0001$ ), and a larger proportion of poor outcomes (ie, discharge mRS score $>2,73.7$ vs 54.9\%; OR: 2.6, standard error (SE): $0.5, \mathrm{z}=4.82, p<0.0001 ; 95 \% \mathrm{CI}: 1.8-3.9$ ). The extent of recovery during hospitalization estimated by the difference between NIHSS scores at discharge and admission did not differ $(0.5 \pm 8.8$ vs $1.1 \pm 0.7 .4 ; p=0.26)$. There was a significantly larger proportion of minor strokes ${ }^{29}$ (ie, initial NIHSS score $<4$ ) in non-PDPD patients (22.1 vs $41.2 \%$; OR: 0.38 , SE: $0.08, \mathrm{z}=-4.89, p<0.0001$; 95\% CI: $0.26-0.56)$. There were no differences regarding acute treatment, in particular the utilization of intravenous systemic thrombolysis ( 29.4 vs $26.9 \% ; p=0.51$ ) or thrombectomy ( 8.9 vs $10.4 \%$; $p=0.55$ ) for ischemic stroke between the groups. The portion of PDPD patients discharged home to live independently did not differ from non-PDPD patients ( 8.0 vs $10.4 \%$; $p=0.29$ ). Significantly fewer PDPD patients were discharged home with family care (18.1 vs $28.0 \%$; OR: 0.56 , SE: 0.12 , $\mathrm{z}=-2.76, p=0.006$; 95\% CI: $0.37-0.84$ ), but more frequently into institutional care (10.0 vs $1.5 \%$; OR: 7.5 , SE: 3.4, $\mathrm{z}=4.48, p<0.0001 ; 95 \% \mathrm{CI}: 3.1-18.1)$. Eighteen PDPD patients $(9.0 \%)$ died, which differed significantly from nonPDPD patients, where 27 patients died (4.5\%; OR: 2.1, SE: $0.69, \mathrm{z}=2.25, p=0.024$; 95\% CI: $1.10-4.02$ ).

\section{Psychiatric complications}

In general, we found a higher rate of psychiatric complications during the initial treatment phase in PDPD patients compared to non-PDPD patients (46.7 vs $28.9 \%$; OR: -0.78 , SE: 0.2 , $\mathrm{z}=4.59, p<0.0001$; 95\% CI: 0.45-1.12). Delirium and depressive syndromes during hospitalization for acute stroke occurred more frequently in PDPD patients $(p<0.0001$ and $p=0.012$, respectively), as did the initiation of new psychopharmacotherapy of any kind $(p=0.001)$, which was mainly due to significantly more newly prescribed antipsychotics and benzodiazepines (Table 4). The need for physical restraint because of imminent danger to self or others did not differ between the groups and was in all 20 cases due to a delirious syndrome. Almost two-thirds of the cases of delirium occurred in patients with dementia (59.7\%), followed by patients with a pre-existing substance-associated disorder (33.9\%). A 
Table 3 Characteristics of the index stroke and the short-term outcome compared between PDPD and non-PDPD patients

\begin{tabular}{|c|c|c|c|}
\hline & PDPD patients & Non-PDPD patients & $p$-value \\
\hline \multicolumn{4}{|l|}{ Index stroke } \\
\hline Ischemic, n (\%) vs. hemorrhagic stroke, n (\%) & $180(90.4)$ vs. $19(9.6)$ & 557 (93.0) vs. $42(7.0)$ & 0.243 \\
\hline Admission NIHSS score, mean \pm SD & $10.1 \pm 7.9$ & $7.5 \pm 7.4$ & 0.001 \\
\hline Discharge NIHSS score, mean \pm SD & $9.7 \pm 12.0$ & $6.3 \pm 10.0$ & 0.001 \\
\hline NIHSS score difference D-A, mean \pm SD & $0.5 \pm 8.8$ & $\mathrm{I} . \mathrm{I} \pm .7 .4$ & 0.292 \\
\hline Minor stroke $(\mathrm{NIHSS}<4), \mathrm{n}, \%$ & $44(22.1)$ & $247(4 \mid .2)$ & 0.001 \\
\hline Admission mRS score, mean \pm SD & $4.1 \pm 1.1$ & $3.6 \pm 1.3$ & 0.001 \\
\hline Discharge $m R S$ score, mean \pm SD & $3.7 \pm 1.6$ & $2.9 \pm 1.7$ & 0.001 \\
\hline \multicolumn{4}{|l|}{ Acute therapy (ischemic strokes only) } \\
\hline Systemic thrombolysis, n (\%) & $53(29.4)$ & $150(26.9)$ & 0.512 \\
\hline Thrombectomy, n (\%) & $16(8.9)$ & $58(10.4)$ & 0.554 \\
\hline Trial medication, $\mathrm{n}(\%)$ & $2(1.1)$ & $5(0.9)$ & 0.681 \\
\hline Duration of hospitalization, days, mean (SD) & $10.0(0.43)$ & $9.8(0.3 \mathrm{I})$ & 0.764 \\
\hline Poor outcome (discharge mRS >2), n (\%) & $146(73.4)$ & $329(54.9)$ & 0.001 \\
\hline Death $(m R S=6), n(\%)$ & $18(9.0)$ & $27(4.5)$ & 0.016 \\
\hline \multicolumn{4}{|l|}{ Survivors } \\
\hline Home discharge, independent, n (\%) & $16(8.0)$ & $62(10.4)$ & 0.342 \\
\hline Home discharge, family care, n (\%) & $36(18.1)$ & $168(28.0)$ & 0.005 \\
\hline Institutional care, $\mathrm{n}(\%)$ & $20(10.0)$ & $9(1.5)$ & 0.001 \\
\hline Rehabilitation/different hospital, $\mathrm{n}$ (\%) & $109(54.8)$ & $331(55.4)$ & 0.905 \\
\hline
\end{tabular}

Note: Bold data indicate statistical significance.

Abbreviations: mRS, modified Rankin Scale; NIHSS, National Institute of Health Stroke Scale; PDPD, predocumented psychiatric diagnosis.

Table 4 Psychiatric complications during hospitalization for acute stroke compared between PDPD and non-PDPD patients

\begin{tabular}{|l|l|l|l|}
\hline Psychiatric complication & PDPD patients & Non-PDPD patients & P-value \\
\hline Delirium, n (\%) & $62(31.1)$ & $94(15.7)$ & $\mathbf{0 . 0 0 I}$ \\
Depressive syndrome, $\mathrm{n}(\%)$ & $15(7.5)$ & $20(3.3)$ & $\mathbf{0 . 0 1 2}$ \\
Newly prescribed antidepressant, $\mathrm{n}(\%)$ & $15(7.5)$ & $27(4.5)$ & 0.097 \\
Newly prescribed antipsychotic, $\mathrm{n}(\%)$ & $46(23.1)$ & $95(15.9)$ & $\mathbf{0 . 0 2 0}$ \\
Newly prescribed benzodiazepine, $\mathrm{n}(\%)$ & $29(14.6)$ & $42(7.0)$ & $\mathbf{0 . 0 0 1}$ \\
Dosage increase of pre-existing psychiatric medication, $\mathrm{n}(\%)$ & $6(3.0)$ & $1(0.2)$ & $\mathbf{0 . 0 0 1}$ \\
Physical restraint, $\mathrm{n}(\%)$ & $8(4.0)$ & $12(2.0)$ & 0.115 \\
\hline
\end{tabular}

Note: Bold data indicate statistical significance.

Abbreviation: PDPD, predocumented psychiatric diagnosis.

depressive syndrome occurred in 15 PDPD patients, 12 of whom had a predocumented affective disorder. Both a delirious syndrome and a depressive syndrome were diagnosed in seven patients, five of whom had no PDPD.

\section{Subgroup analysis of PDPD patients without dementia}

The exclusion of 69 patients with pre-existing dementia yielded a significant difference in age between patients with a pre-existing psychiatric diagnosis and those without (mean age 67.6 vs 71.8 years, respectively; $p=0.001$ ). No significant differences were found regarding gender and vascular risk factors (hypertension, diabetes, dyslipidemia, KHK, prior myocardial infarction, or stroke - data not shown) except for tobacco consumption (40.0 vs $18.0 \%$ of patients; $p<0.0001)$. Initial clinical deficits were more severe in PDPD patients than in non-PDPD patients (mean NIHSS score $9.1 \pm 7.5$ vs $7.5 \pm 7.4 ; \mathrm{F}(10,727)=8.55$, $p=0.0036$ and median mRS score on admission $3.9 \pm 1.2$ vs $3.6 \pm 1.3 ; \mathrm{F}(10,727)=10.79, p=0.0011)$, and NIHSS scores at discharge differed significantly $(8.7 \pm 12.1$ vs $6.3 \pm 10.0 ; \mathrm{F}$ $(10,727)=10.05, p=0.0016)$, as did mRS on discharge $(3.3$ $\pm 1.7 \quad$ vs $2.9 \pm 1.7 ; \quad \mathrm{F}(10,727)=11.92, \quad p=0.0006)$. Minor strokes were found more frequently in non-PDPD patients 
(41.2 vs $27.7 \%$; OR: 0.48 , SE: $0.11, \mathrm{z}=-3.29, p=0.001$; 95\% CI: $0.31-0.74$ ), while poor functional outcome was found more frequently in PDPD patients (61.5 vs 54.9\%; OR: 1.73, SE: $0.38, \mathrm{z}=2.46, p=0.014 ; 95 \% \mathrm{CI}: 1.12-2.67$ ). Delirium was equally prevalent in PDPD and non-PDPD patients (19.2 vs $15.7 ; p=0.17$ ), but more depressive syndromes were diagnosed in PDPD patients (11.5 vs 3.3; OR: 3.09, SE: $1.16, \mathrm{z}=3.00, p=0.003$; $95 \%$ CI: $1.48-6.46$ ).

\section{Discussion}

In our retrospective analysis of patients with ischemic and hemorrhagic stroke, we found more severe strokes and a higher prevalence of poor outcomes as well as a higher rate of psychiatric complications during the initial treatment phase in patients with a PDPD than in those without. Moreover, when excluding patients with predocumented dementia, whose categorization as neurodegenerative diseases in the category of "psychiatric diseases" could be argued, a significant age difference between PDPD and non-PDPD patients emerged, corroborating data by Chiu et $\mathrm{al}^{30}$ who found a higher risk for stroke in adults younger than 45 years of age and with pre-existing mental disorder. ${ }^{30}$ At the same time, initial stroke severity was more pronounced and poor outcomes were more frequent in nondemented PDPD patients.

A large body of data supports the notion of mental illness as a - potentially modifiable - stroke risk factor. Patients with bipolar disorder, ${ }^{26}$ schizophrenia, ${ }^{19}$ alcohol use, $^{31}$ and illicit drug use ${ }^{32}$ have an increased risk for stroke. Limited data exist on the relation between anxiety disorders and stroke incidence. ${ }^{33}$ However, there is a scarcity of studies investigating the relationship between prestroke psychiatric morbidity and the severity of stroke or outcome after stroke: two groups demonstrated associations between prestroke depression and stroke severity as well as functional outcome. ${ }^{11,12}$ Data on the impact of prestroke dementia on stroke severity and outcome are also consistent in that pre-existing dementia is associated with a higher burden of disability and higher rates of institutionalization after stroke. ${ }^{34-36}$ Aron et $\mathrm{al}^{37}$ found the living situation prior to stroke and ensuing social isolation, ${ }^{37}$ which is more frequent in the mentally ill, ${ }^{38}$ to contribute to the initial stroke severity. In our cohort, significantly more PDPD patients lived in family or institutional care prior to the index stroke. This does not preclude a relevant influence of social isolation since the quality of social involvement appears to be inadequately reflected by merely considering patients' living situation. ${ }^{37}$
Prieto et $\mathrm{al}^{17}$ hypothesize that patients with depression lead an unhealthier lifestyle, which in turn may be associated with higher prevalence of other risk factors for stroke. ${ }^{17}$ In a study examining diabetic patients, alcohol consumption was identified as a relevant contributor to the severity of stroke and outcome in these patients. ${ }^{39}$ In our sample, the prevalence of vascular risk factors did not differ between stroke patients with and without psychiatric premorbidity except for smoking, supporting the wellestablished fact that smoking is more common in psychiatric patients than in the general population. ${ }^{40}$ However, even though cigarette smoking is an established risk factor for stroke, ${ }^{41}$ data regarding the contribution of smoking to stroke severity are inconsistent. ${ }^{42-45}$ Unfortunately, we did not have information on our patients' body mass index, which would have been valuable in light of the association of obesity and mental health, on the one hand, ${ }^{46}$ and obesity and prognosis after stroke, on the other. ${ }^{47-49}$ For patients with premorbid psychiatric diagnoses, several studies have demonstrated increased morbidity and mortality from acute medical conditions, such as prolonged hospitalization, worse cardiac adverse events, and mortality after acute coronary syndrome. ${ }^{50}$ Liao et $\mathrm{al}^{51}$ found higher rates of postoperative complications and mortality rates in patients suffering from schizophrenia. ${ }^{51}$ Data unadjusted for sociodemographics and comorbidity indicate that mentally ill stroke survivors were more frequently hospitalized for nonpsychiatric reasons prior to and up to one year after their initial stroke. ${ }^{52}$ Patients with atrial fibrillation and schizophrenia or severe depression experienced increased rates of stroke and major bleeding compared with matched comparisons, ${ }^{53}$ and coagulation control is poorer in mentally ill patients. ${ }^{54}$ On a related note, Blackburn et $\mathrm{al}^{55}$ showed that statins do not lower the risk for cardiovascular disease in psychiatric patients. ${ }^{55}$ Insufficient power of that study may be one reason for this finding; however, concomitant psychopharmacotherapy may interact with lipid-lowering agents and diminish their efficacy. ${ }^{56}$ Finally, adherence to medication may be problematic in patients with a mental disorder or cognitive impairment, ${ }^{57}$ which may impact on prescription practices. ${ }^{58} \mathrm{~A}$ recent meta-analysis investigating the association between cognitive impairment and medication adherence in stroke survivors, ${ }^{59}$ however, suggests that it may be useful to differentiate degrees of cognitive impairment with more severely affected patients' adherence actually being improved by their reliance on caregivers. Inequalities regarding the initiation of treatments have also been 
noted with respect to acute stroke treatment: a recent study reports lower rates of thrombolysis in patients with a psychiatric diagnosis, ${ }^{60}$ a finding we could not support in our sample. In our study, PDPD patients mainly received antidepressant and antipsychotic medication as prestroke psychopharmacotherapy. Prestroke use of antipsychotic medication was found to be associated with a higher risk for severe strokes and higher poststroke mortality, ${ }^{61}$ and serotonin reuptake inhibitors also negatively impacted on stroke outcome with a trend-level negative influence on initial stroke severity. ${ }^{62}$ Hence, medication may be one factor contributing to more severe strokes in PDPD patients.

Limitations of our study are predominantly tied to its retrospective design where comprehensiveness and quality of the source data are of paramount importance. As a certified stroke unit, the stroke unit of University Medical Centre, Mannheim, Germany has to meet certain standards regarding completeness of data required by the German Stroke Society. ${ }^{63}$ Identification of psychiatric premorbidity by patient record and documentation may have missed patients with a psychiatric diagnosis. Psychiatric conditions are frequently under-recognized, misdiagnosed, or undertreated, and nonpsychiatrists' accuracy in recognizing psychiatric disorders does not improve over time without specific training. ${ }^{64}$ We furthermore did not distinguish between active versus remote history of psychiatric disorder, and we did not have information regarding the duration of and compliance to current psychopharmacotherapy as well as comprehensive data pertaining to past hospitalizations for psychiatric disorder, which would have been interesting in the context of Zuflacht et al's ${ }^{28}$ research showing an association between time of last psychiatric hospitalization and timing of stroke. ${ }^{28}$ It would also have been desirable to have standardized follow-up evaluations after seven and 90 days to investigate the longer-term outcome. This would have been particularly informative for stroke survivors discharged to a different hospital or into rehabilitative treatment. Depressive or delirious syndromes during hospitalization for acute stroke were clinically diagnosed, which contrasts with Diagnostic and Statistical Manual of Mental Disorders, 5th edition and ICD-10 definitions for a depressive episode and the required minimum of symptom duration. However, on the grounds of clinical impression, antidepressant medication is frequently initiated early after stroke, which has been shown to positively influence shortterm mortality in ischemic stroke. ${ }^{65}$ We are also well aware that the strategy of conflating patients with different predocumented psychiatric diagnoses into one group may overgeneralize, and thus neglect idiosyncrasies of specific psychiatric disorders regarding their impact on the acute natural history of stroke.

\section{Conclusion}

In summary, we found more severe strokes and higher prevalence of poor outcome in patients with a documented psychiatric diagnosis at the time of stroke, as well as a higher rate of psychiatric complications during the initial treatment phase. In the light of a recently identified association between the number of mental disorders and the incidence of nonfatal stroke, it is recommended to obtain a mental health history of stroke patients in order to evaluate extent and persistence of premorbid psychopathology, ${ }^{27}$ and patients with a pre-existing psychiatric disorder should be particularly closely monitored for poststroke psychiatric complications.

\section{Acknowledgment}

LK received support from the German Research Foundation (DFG; grant number KR 4689/3-1).

\section{Disclosure}

The authors report no conflict of interest in this work.

\section{References}

1. Mozaffarian D, Benjamin EJ, Go AS, et al. Heart disease and stroke statistics-2016 update: a report from the American Heart Association. Circulation. 2016;133(4):e38-360. doi:10.1161/ CIR.0000000000000350

2. Lopez AD, Mathers CD, Ezzati M, Jamison DT, Murray CJ. Global and regional burden of disease and risk factors, 2001: systematic analysis of population health data. Lancet. 2006;367(9524):17471757. doi:10.1016/S0140-6736(06)68770-9

3. Dougu N, Takashima S, Sasahara E, et al. Predictors of poor outcome in patients with acute cerebral infarction. J Clin Neurol. 2011;7 (4):197-202. doi:10.3988/jcn.2011.7.4.197

4. Sarwar N, Gao P, Seshasai SR, et al. Diabetes mellitus, fasting blood glucose concentration, and risk of vascular disease: a collaborative meta-analysis of 102 prospective studies. Lancet. 2010;375 (9733):2215-2222. doi:10.1016/S0140-6736(10)60484-9

5. Elkind MS. Epidemiology and risk factors. Continuum (Minneap Minn). 2011;17(62ndary Stroke Prevention):1213-1232. doi:10.1212/ 01.CON.0000410031.34477.8d

6. Weimar C, Ziegler A, Konig IR, Diener HC. Predicting functional outcome and survival after acute ischemic stroke. J Neurol. 2002;249 (7):888-895. doi:10.1007/s00415-002-0755-8

7. Appelros P, Nydevik I, Seiger A, Terent A. Predictors of severe stroke: influence of preexisting dementia and cardiac disorders. Stroke. 2002;33(10):2357-2362.

8. Protopsaltis J, Kokkoris S, Korantzopoulos P, et al. Prediction of long-term functional outcome in patients with acute ischemic nonembolic stroke. Atherosclerosis. 2009;203(1):228-235. doi:10.1016/ j.atherosclerosis.2008.05.042 
9. Hackett ML, Pickles K. Part I: frequency of depression after stroke: an updated systematic review and meta-analysis of observational studies. Int J Stroke. 2014;9(8):1017-1025. doi:10.1111/ijs.12357

10. Robinson RG, Jorge RE. Post-stroke depression: a review. Am J Psychiatry. 2016;173(3):221-231. doi:10.1176/appi.ajp.2015.15030363

11. Sharrief AZ, Sanchez BN, Lisabeth LD, et al. The impact of prestroke depressive symptoms, fatalism, and social support on disability after stroke. J Stroke Cerebrovasc Dis. 2017;26(11):2686-2691. doi:10.1016/j.jstrokecerebrovasdis.2017.06.039

12. Naess H, Lunde L, Brogger J, Waje-Andreassen U, Depression predicts unfavourable functional outcome and higher mortality in stroke patients: the Bergen Stroke study. Acta Neurol Scand Suppl. 2010;190:34-38. doi:10.1111/j.1600-0404.2010.01373.x

13. Willers C, Sunnerhagen KS, Lekander I, von Euler M. The association of pre-stroke psychosis and post-stroke levels of health, resource utilization, and care process: a register-based study. Front Neurol. 2018;9:1042. doi:10.3389/fneur.2018.01042

14. Pendlebury ST, Rothwell PM. Prevalence, incidence, and factors associated with pre-stroke and post-stroke dementia: a systematic review and meta-analysis. Lancet Neurol. 2009;8(11):1006-1018. doi:10.1016/S1474-4422(09)70236-4

15. McManus J, Pathansali R, Stewart R, Macdonald A, Jackson S. Delirium post-stroke. Age Ageing. 2007;36(6):613-618. doi:10.1093/ageing/ afm140

16. Ferro JM, Caeiro L, Figueira ML. Neuropsychiatric sequelae of stroke. Nat Rev Neurol. 2016;12(5):269-280. doi:10.1038/nrneurol.2016.46

17. Prieto ML, Schenck LA, Kruse JL, et al. Long-term risk of myocardial infarction and stroke in bipolar I disorder: a population-based Cohort Study. J Affect Disord. 2016;194:120-127. doi:10.1016/j.jad.2016.01.015

18. Valkanova V, Ebmeier KP. Vascular risk factors and depression in later life: a systematic review and meta-analysis. Biol Psychiatry. 2013;73(5):406-413. doi:10.1016/j.biopsych.2012.10.028

19. Li M, Fan YL, Tang ZY, Cheng XS. Schizophrenia and risk of stroke: a meta-analysis of cohort studies. Int J Cardiol. 2014;173(3):588590. doi:10.1016/j.ijcard.2014.03.101

20. Leboyer M, Soreca I, Scott J, et al. Can bipolar disorder be viewed as a multi-system inflammatory disease? J Affect Disord. 2012;141 (1):1-10. doi:10.1016/j.jad.2011.12.049

21. Nemeroff CB, Goldschmidt-Clermont PJ. Heartache and heartbreakthe link between depression and cardiovascular disease. Nat Rev Cardiol. 2012;9(9):526-539. doi:10.1038/nrcardio.2012.91

22. Moises HW, Wollschlager D, Binder H. Functional genomics indicate that schizophrenia may be an adult vascular-ischemic disorder. Transl Psychiatry. 2015;5:e616. doi:10.1038/tp.2015.103

23. Chen WY, Chen LY, Liu HC, et al. Antipsychotic medications and stroke in schizophrenia: a case-crossover study. PLoS One. 2017;12 (6):e0179424. doi:10.1371/journal.pone.0179424

24. Pan A, Sun Q, Okereke OI, Rexrode KM, Hu FB. Depression and risk of stroke morbidity and mortality: a meta-analysis and systematic review. Jama. 2011;306(11):1241-1249. doi:10.1001/jama.2011.1282

25. Pendlebury ST. Dementia in patients hospitalized with stroke: rates, time course, and clinico-pathologic factors. Int J Stroke. 2012;7 (7):570-581. doi:10.1111/j.1747-4949.2012.00837.x

26. Prieto ML, Cuellar-Barboza AB, Bobo WV, et al. Risk of myocardial infarction and stroke in bipolar disorder: a systematic review and exploratory meta-analysis. Acta Psychiatr Scand. 2014;130(5):342353. doi:10.1111/acps. 12293

27. Swain NR, Lim CC, Levinson D, et al. Associations between DSM-IV mental disorders and subsequent non-fatal, self-reported stroke. J Psychosom Res. 2015;79(2):130-136. doi:10.1016/j. jpsychores.2015.05.008

28. Zuflacht JP, Shao Y, Kronish IM, et al. Psychiatric hospitalization increases short-term risk of stroke. Stroke. 2017;48(7):1795-1801. doi:10.1161/STROKEAHA.116.016371
29. Fischer U, Baumgartner A, Arnold $\mathrm{M}$, et al. What is a minor stroke? Stroke. 2010;41(4):661-666. doi:10.1161/STROKEAHA. 109.572883

30. Chiu YC, Bai YM, Su TP, Chen TJ, Chen MH. Ischemic stroke in young adults and preexisting psychiatric disorders: a nationwide case-control study. Medicine (Baltimore). 2015;94(38):e1520. doi:10.1097/MD.0000000000000874

31. Reynolds K, Lewis B, Nolen JD, Kinney GL, Sathya B, He J. Alcohol consumption and risk of stroke: a meta-analysis. Jama. 2003;289(5):579-588.

32. Esse K, Fossati-Bellani M, Traylor A, Martin-Schild S. Epidemic of illicit drug use, mechanisms of action/addiction and stroke as a health hazard. Brain Behav. 2011;1(1):44-54. doi:10.1002/ brb3.7

33. Lambiase MJ, Kubzansky LD, Thurston RC. Prospective study of anxiety and incident stroke. Stroke. 2014;45(2):438-443. doi:10.1161/STROKEAHA.113.003741

34. Desmond DW, Moroney JT, Sano M, Stern Y. Mortality in patients with dementia after ischemic stroke. Neurology. 2002;59(4):537-543. doi:10.1212/wnl.59.4.537

35. Garcia-Ptacek S, Contreras Escamez B, Zupanic E, et al. Prestroke mobility and dementia as predictors of stroke outcomes in patients over 65 years of age: a cohort study from the Swedish dementia and stroke registries. J Am Med Dir Assoc. 2018;19(2):154-161. doi:10.1016/j.jamda.2017.08.014

36. Saposnik G, Kapral MK, Cote R, et al. Is pre-existing dementia an independent predictor of outcome after stroke? A propensity scorematched analysis. J Neurol. 2012;259(11):2366-2375. doi:10.1007/ s00415-012-6508-4

37. Aron AW, Staff I, Fortunato G, McCullough LD. Prestroke living situation and depression contribute to initial stroke severity and stroke recovery. J Stroke Cerebrovasc Dis. 2015;24(2):492-499. doi:10.1016/j.jstrokecerebrovasdis.2014.09.024

38. Linz SJ, Sturm BA. The phenomenon of social isolation in the severely mentally ill. Perspect Psychiatr Care. 2013;49(4):243-254. doi: $10.1111 /$ ppc. 12010

39. Natuva SSK, Tirupati S, Reddy AP. Independent predictors of severity and functional outcome of acute ischemic stroke in patients with diabetes. J Neurol Exp Neurosci. 2016;2(1):15-20.

40. Aubin HJ, Rollema H, Svensson TH, Winterer G. Smoking, quitting, and psychiatric disease: a review. Neurosci Biobehav Rev. 2012;36 (1):271-284. doi:10.1016/j.neubiorev.2011.06.007

41. Shah RS, Cole JW. Smoking and stroke: the more you smoke the more you stroke. Expert Rev Cardiovasc Ther. 2010;8(7):917-932. doi:10.1586/erc. 10.56

42. Bejot Y, Jacquin A, Daubail B, et al. Smoking status and severity of ischemic stroke. A population-based study. Eur Neurol. 2014;71(12):59-64. doi:10.1159/000355021

43. Edjoc RK, Reid RD, Sharma M, Fang J; Registry of the Canadian Stroke N. The prognostic effect of cigarette smoking on stroke severity, disability, length of stay in hospital, and mortality in a cohort with cerebrovascular disease. J Stroke Cerebrovasc Dis. 2013;22(8):e446-e454. doi:10.1016/j.jstrokecerebrovasdis.2013.05.001

44. Fekete K, Szatmari S, Szocs I, et al. Prestroke alcohol consumption and smoking are not associated with stroke severity, disability at discharge, and case fatality. J Stroke Cerebrovasc Dis. 2014;23(1): e31-e37. doi:10.1016/j.jstrokecerebrovasdis.2013.08.006

45. Weng WC, Huang WY, Chien YY, et al. The impact of smoking on the severity of acute ischemic stroke. J Neurol Sci. 2011;308(12):94-97. doi:10.1016/j.jns.2011.05.046

46. Avila C, Holloway AC, Hahn MK, et al. An overview of links between obesity and mental health. Curr Obes Rep. 2015;4(3):303310. doi:10.1007/s13679-015-0164-9 
47. Branscheidt M, Schneider J, Michel P, et al. No impact of body mass index on outcome in stroke patients treated with IV thrombolysis BMI and IV thrombolysis outcome. PLoS One. 2016;11(10): e0164413. doi:10.1371/journal.pone.0164413

48. Sarikaya H, Elmas F, Arnold M, Georgiadis D, Baumgartner RW. Impact of obesity on stroke outcome after intravenous thrombolysis. Stroke. 2011;42(8):2330-2332. doi:10.1161/STROKEAHA.110.599613

49. Strazzullo P, D’Elia L, Cairella G, Garbagnati F, Cappuccio FP, Scalfi L. Excess body weight and incidence of stroke: meta-analysis of prospective studies with 2 million participants. Stroke. 2010;41(5): e418-e426. doi:10.1161/STROKEAHA.109.576967

50. Protty MB, Lacey A, Smith D, Hannoodee S, Freeman P. Increased morbidity, mortality and length of in-hospital stay for patients with acute coronary syndrome with pre-morbid psychiatric diagnoses. Int J Cardiol. 2017;236:5-8. doi:10.1016/j.ijcard.2017.01.067

51. Liao CC, Shen WW, Chang CC, Chang H, Chen TL. Surgical adverse outcomes in patients with schizophrenia: a population-based study. Ann Surg. 2013;257(3):433-438. doi:10.1097/SLA.0b013e31827b9b25

52. Lilly FR, Culpepper J, Stuart M, Steinwachs D. Stroke survivors with severe mental illness: are they at-risk for increased non-psychiatric hospitalizations? PLoS One. 2017;12(8):e0182330. doi:10.1371/journal.pone. 0182330

53. Sogaard M, Skjoth F, Kjaeldgaard JN, Larsen TB, Hjortshoj SP, Riahi $\mathrm{S}$. Atrial fibrillation in patients with severe mental disorders and the risk of stroke, fatal thromboembolic events and bleeding: a nationwide cohort study. BMJ Open. 2017;7(12):e018209. doi:10.1136/ bmjopen-2017-018209

54. Paradise HT, Berlowitz DR, Ozonoff A, et al. Outcomes of anticoagulation therapy in patients with mental health conditions. $J$ Gen Intern Med. 2014;29(6):855-861. doi:10.1007/s11606-014-2784-2

55. Blackburn R, Osborn D, Walters K, Falcaro M, Nazareth I, Petersen I. Statin prescribing for people with severe mental illnesses: a staggered cohort study of 'real-world' impacts. BMJ Open. 2017;7(3): e013154. doi:10.1136/bmjopen-2016-013154
56. Horton JD, Goldstein JL, Brown MS. SREBPs: activators of the complete program of cholesterol and fatty acid synthesis in the liver. J Clin Invest. 2002;109(9):1125-1131. doi:10.1172/JCI15593

57. Osterberg L, Blaschke T. Adherence to medication. $N$ Engl J Med. 2005;353(5):487-497. doi:10.1056/NEJMra050100

58. Macklin J, Morrison G. Survey of general practitioners' attitudes to prescribing statins in different patient groups: a web-based survey. Scott Med J. 2011;56(1):33-35. doi:10.1258/smj.2010.010016

59. Rohde D, Merriman NA, Doyle F, Bennett K, Williams D, Hickey A. Does cognitive impairment impact adherence? A systematic review and meta-analysis of the association between cognitive impairment and medication non-adherence in stroke. PLoS One. 2017;12(12): e0189339. doi:10.1371/journal.pone.0189339

60. Bongiorno DM, Daumit GL, Gottesman RF, Faigle R. Comorbid psychiatric disease is associated with lower rates of thrombolysis in ischemic stroke. Stroke. 2018;49(3):738-740. doi:10.1161/ STROKEAHA.117.020295

61. Prior A, Laursen TM, Larsen KK, et al. Post-stroke mortality, stroke severity, and preadmission antipsychotic medicine use-a populationbased cohort study. PLoS One. 2014;9(1):e84103. doi:10.1371/journal.pone.0084103

62. Etherton MR, Siddiqui KA, Schwamm LH. Prestroke selective serotonin reuptake inhibitor use and functional outcomes after ischaemic stroke. Stroke Vasc Neurol. 2018;3(1):9-16. doi:10.1136/svn-2017-000119

63. Nabavi DG, Koennecke HC, Ossenbrink M, Grau A, Busse O. [Certification criteria for stroke units in Germany: update 2018]. Nervenarzt. 2019;90(4):335-342. doi:10.1007/s00115-018-0633-y

64. Su JA, Tsai CS, Hung TH, Chou SY. Change in accuracy of recognizing psychiatric disorders by non-psychiatric physicians: five-year data from a psychiatric consultation-liaison service. Psychiatry Clin Neurosci. 2011;65(7):618-623. doi:10.1111/j.1440-1819.2011.02272.x

65. Mortensen JK, Johnsen SP, Larsson H, Andersen G. Early antidepressant treatment and all-cause 30-day mortality in patients with ischemic stroke. Cerebrovasc Dis. 2015;40(1-2):81-90. doi:10.1159/000435819
Neuropsychiatric Disease and Treatment

\section{Publish your work in this journal}

Neuropsychiatric Disease and Treatment is an international, peerreviewed journal of clinical therapeutics and pharmacology focusing on concise rapid reporting of clinical or pre-clinical studies on a range of neuropsychiatric and neurological disorders. This journal is indexed on PubMed Central, the 'PsycINFO' database and CAS, and is the official journal of The International Neuropsychiatric Association (INA). The manuscript management system is completely online and includes a very quick and fair peer-review system, which is all easy to use. Visit http://www.dovepress.com/testimonials.php to read real quotes from published authors. 